EESTI NSV TEADUSTE AKADEEMIA TOIMETISED. XV KÖIDE FUUSIKA-MATEMAATIKA- JA TEHNIKATEADUSTE SEERIA. 1966, NR. 3

ИЗВЕСТИЯ АКАДЕМИИ НАУК ЭСТОНСКОН ССР. ТОМ ХV СЕРИЯ ФИЗИКО-МАТЕМАТИЧЕСҚИХ И ТЕХНИЧЕСКИХ НАУК. 1966, № 3

\title{
ИССЛЕДОВАНИЕ ИМПУЛЬСНОГО РАЗРЯДА В ЖИДКОСТЯХ РАЗЛИЧНОИ ЭЛЕКТРОПРОВОДНОСТИ
}

Явленил, возникающие при импульсном электрическом разряде в жидкостях, представляют значительный теоретический и практический интерес и привлекают в последние годы внимание многих исследователей $\left[{ }^{1-6}\right.$. На ряд основных вопросов, связанных с механизмом развития искрового разряда в жидкостях, однозначные ответы до сих пор не получены и некоторые выводы из исследований противоречивы.

В настоящей статье освещены основные результаты экспериментального исследования развития импульсных разрядов высокого напряжения в водных средах с различной прозодимостью. При этом оценивается также мало изученная ранее эффективность воздействия разрядов различюого характера и параметров на физико-химические процессы, протекающие в жидкости.

\section{Методика эксперимента}

Для исследования использовалась импульсная высоковольтная установка, позволяющая изменять параметры разряда в широком диапазоне: напряжение с крутым фронтом $\tau_{\phi} 10^{-7}$ сек до $50 \kappa$, емкость от 0,0044 до 2,4 мкф, индуктивность контура - от 1,4 до 4,5 жкгн. Исследование проведено в герметичных реакторах (бронзовом, стальном, полиэтиленовом) цилиндрической формы различной емкости с отверстиями для производства фотоснимков, отбора проб газа и жидкости. Процесс разряда изучен для несимметричного промежутка типа острие-плоскость и острие-острие при расстоянии от 5 до 40 м.м.

Сигналы тока и напряжения подаются на пластины модифицированного нами осциллографа OK-17. Микросекундные метки времени подавались на осциллограф от генератора ГС-100И. Сигналы тока снимаются с безындукционных трубчатых шунтов. В зависимости от параметров разрядной цепи применялись шунты с сопротивлением 0,0135 и 0,00218 ом с постоянной времени $10^{-7}$ сек.

Напряжение на разрядном промежутке подавалось на осциллограф через емкостный или омнческий делитель, подключенный непосредственно к зажимам реактора. Однако исследования показали необходимость осуществления компенсации индуктивной составляющей напряжения на делители:

Канал разряда, как самосветящийся объект, фотографировался на пленки различной чувствительности с изменением диафрагмы и с применением различных светофильтров.

Обработка осциллограмм и интегральных фотоснимков дает возможность рассчитать характеристики разряда: зависимость мощности $P(t)=i(t) v(t)$; энергии, выделяющейся в зоне разряда от времени $W(t)=\int_{0}^{\tau} i(t) v(t) d t ;$ кПд процесса $\eta=W_{1} / W_{c}$, где 
$W_{1}$ - энергия, выделившаяся за первый полупериод прохождения тока, $W_{c}$ - энергия, запасенная в конденсаторах к моменту разряда $W_{c}=c u^{2} / 2$; скорость распространения разряда $V_{\text {cp }}=l / t_{\mathrm{np}} ;$ эквивалентное сопротивление контура $R_{\ni}=2 L \ln J_{1} / J_{2}$; декримент затухания $-d=-\ln J_{2} / J_{1}$ и другие.

При исследовании импульсных разрядов использованы дозиметрические жидкости, применяемые в радиационной химии: кислый ферросульфатный стандартный раствор Фрике $\gamma=0,1 \quad o M^{-1} \cdot c M^{-1}$, нейтральный водный раствор метиленового голубого $\gamma=5 \cdot 10^{-5} O M^{-1} \cdot c M^{-1}$ и дистиллированная аэрированная вода $\gamma=10^{-5} o M^{-1} \cdot c M^{-1}\left[{ }^{7}\right]$.

\section{РЕЗУЛЬТАТЫ ЭКСПЕРИМЕНТОВ И ИХ ОБСУЖДЕНИЕ}

\section{Характеристика разрядов и их воздействие на среду}

Исследование осциллограмм и сопоставление их с интегральными фотоснимками позволяют разделить результаты экспериментов по характеру разряда на три группы. Каждая из них соответствует определенному комплексу физико-химических процессов, происходящих в жидкости.

K первой группе относятся режимы, где нет плазменного пробоя. Осциллограммы отличаются стабильностью и свидетельствуют о стекании заряда конденсаторов в среду. Следует различать два режима стекания во времени:

а. Режим стекания заряда конденсаторов по экспотенциальному закону на неизменяющееся, либо незначительно изменяющееся сопротивление среды (рис. 1, I $a$ ). Длительность стекания заряда исчисляется миллисекундами, а токи не превышают нескольких ампер. В жидкости не наблюдается свечения, отсутствуют активные процессы, приводящие к изменению состояния среды. Введение в разрядный промежуток значительной энергии приводит лишь к увеличению температуры среды.

Так, подача 20 тысяч импульсов с $C=0,0044$ мкф, $U=30 \kappa в$, $l=15$ мм и частотой следования 300 uмn/cек не приводит к изменению концентрации метиленового голубого в растворе, хотя вводимая в раствор энергия достигла $2 \cdot 10^{20}$ эв/мл. Аналогичные результаты получены в опытах с дистиллированной водой при энергии $6 \cdot 10^{21} э 8 /$ лл. Увеличение одной только поверхности контактной части острия без изменения условий опыта $(U=30 \kappa в, C=0,6$ мкф, $l=15$ мм $\stackrel{+}{\rightarrow} \mapsto)$ приводит к изменению физического процесса разряда: вместо плазменного пробоя происходит стекание заряда. Вода не подвергается разложению, не образуются также молекулярные продукты $\mathrm{H}_{2} \mathrm{O}_{2}$ и $\mathrm{H}_{2}$.

б. Режим стекания заряда конденсаторов в сильнопроводящих жидкостях с $y>0,1 \mathrm{oM}^{-1} \cdot \mathrm{CM}-1$ (рис. $\left.1, \mathrm{I} б\right)$.

Осциллограммы фиксируют высокие значения токов, текущих через раствор (измеряемых в килоамперах), и скоростей стекания (исчисляемых микросекундами). Сопротивление межэлектродного пространства равно или меньше критического сопротивления контура. В этом случае возникает широкая сеть самосветящихся ветвей. Они развиваются в глубь разрядного пространства и приводят $к$ возникновению в среде мощных ионизационных процессов. Это подтверждается результатами опытов с раствором Фрике.

Во вторую и третью груп пы объединяются режимы, в которых развитие разряда завершается пробоем. При режимах второй группы разряд носит апериодический характер: сопротивление канала остается выше критического сопротивления контура (рис. 1, II). В третью труппу включаются "режимы с разрядами периодически-затухающего 
характера (рис. 1, III). Основные показатели для обеих групп представлены в табл. 1. Для каждой группы характерно наличие двух основных последовательных стадий развития разряда, которые отличаются распределением энергии и физико-химическим воздействием на среду.

Таблица $I$

Основные показатели импульсных разрядов в растворе метиленового голубого $\gamma=10^{-5} \mathrm{om}^{-1} \cdot \mathrm{CM}-1 \quad(U=30 \kappa в, l=15$ м. $)$

\begin{tabular}{|c|c|c|c|c|c|c|}
\hline & \multicolumn{3}{|c|}{$\begin{array}{c}\text { Периодически } \\
\text { затухаюший } \\
\text { разряд }\end{array}$} & \multicolumn{3}{|c|}{$\begin{array}{c}\text { Апериодический } \\
\text { разряд }\end{array}$} \\
\hline & \multicolumn{6}{|c|}{ Емкость, $м к ф$} \\
\hline ì & 0,1 & 0,6 & 1,2 & 0.1 & 0,6 & 1,2 \\
\hline 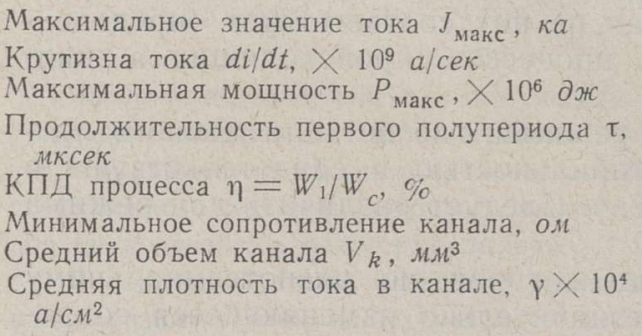 & $\begin{array}{l}2,5 \\
2,1 \\
20 \\
2,75 \\
75 \\
2,0 \\
70 \\
6,8\end{array}$ & $\begin{array}{l}7,1 \\
4,0 \\
52 \\
4,75 \\
36 \\
0,15 \\
220 \\
4,1\end{array}$ & $\begin{array}{l}10,6 \\
5,8 \\
75 \\
7,2 \\
25 \\
0,09 \\
660 \\
2,5\end{array}$ & $\begin{array}{c}1,4 \\
0.9 \\
17 \\
\\
3.2 \\
92 \\
5.8 \\
100 \\
-\end{array}$ & $\begin{array}{c}4,1 \\
2,2 \\
45 \\
\\
6,3 \\
60 \\
2,8 \\
400 \\
-\end{array}$ & $\begin{array}{c}6,4 \\
3,0 \\
65 \\
\\
8.2 \\
53 \\
1,2 \\
840\end{array}$ \\
\hline
\end{tabular}

При меч ан ие. Каждое значение, приведенное в таблице, является средним из 15-20 измеренных и расчетных данных.

Первая - предпробивная стадия - длится с момента приложения напряжения до резкого спада. В ней, как показано ниже, развиваются ионизационные процессы и идет формирование одного или нескольких проводящих каналов. Явления, имеющие место в этой стадии, изменяют конфигурацию поля и обусловливают характер развития второй стадии.

Апериодические разряды отличаются от периодически затухающих большей длительностью и относительно высокими предразрядными токами. Следует ожидать, что апериодическим разрядам предшествуют интенсивные ионизационные процессы, охватывающие значительный объем межэлектродного пространства.

Вторая стадия характеризуется срывом напряжения, броском тока, резким выделением энергии, сильным световым излучением, высокой температурой, возникновением плазмы, ее расширением и перерастанием в парогазовый пузырь, образованием и распространенйем ударных волн. Әлектрическая энергия преобразуется в энергию ударной волны и внутреннюю энергию накала. В эту стадию можно включить и послеразрядные прошессы.

Отличительными особенностями апериодического разряда по сравнению с периодически-затухающими являются: увеличение протяженности и продолжительности существования плазмы, меньшие амплитудные значения тока и скорости его нарастания, более пологий спад напряжения, сниженные скорости поступления энергии в плазму (табл. 2). На рис. 2 представлены изменения мощности, энергии, поступающей в канал, и сопротивление канала к данному моменту времени в зависимости от разрядной емкости для раствора метиленового голубого. 

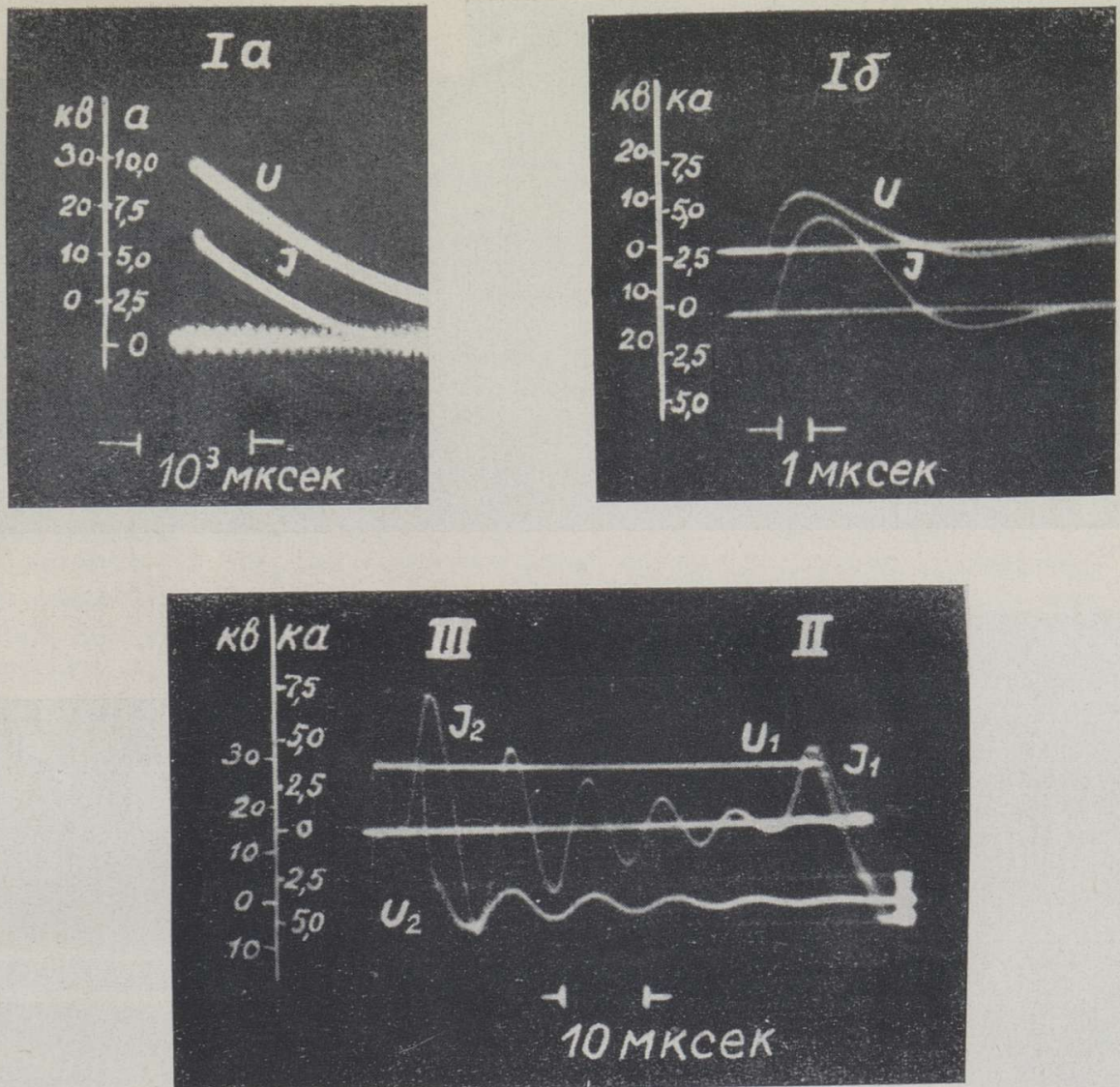

Рис. 1. Осциллограммы напряжения и тока при различных режимах. Межэлектродное расстояние $l=15$ мм $\rightarrow-; C=0,6$ мкф; $U=30 \kappa в$. I $a$ стекание заряда при $\gamma=10^{-5} \mathrm{om}^{-1} \cdot c \boldsymbol{M}^{-1}$ и $S_{\text {остр }}=8 \mathrm{cM^{2 }}$; I $\sigma$ - стекание

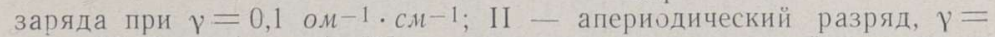
$=10^{-5}$ oм-1 $^{-1} c M^{-1}$; III - периодически-затухающий разряд; $\gamma=10^{-5}$ o. $-1 \cdot C M^{-1}$.
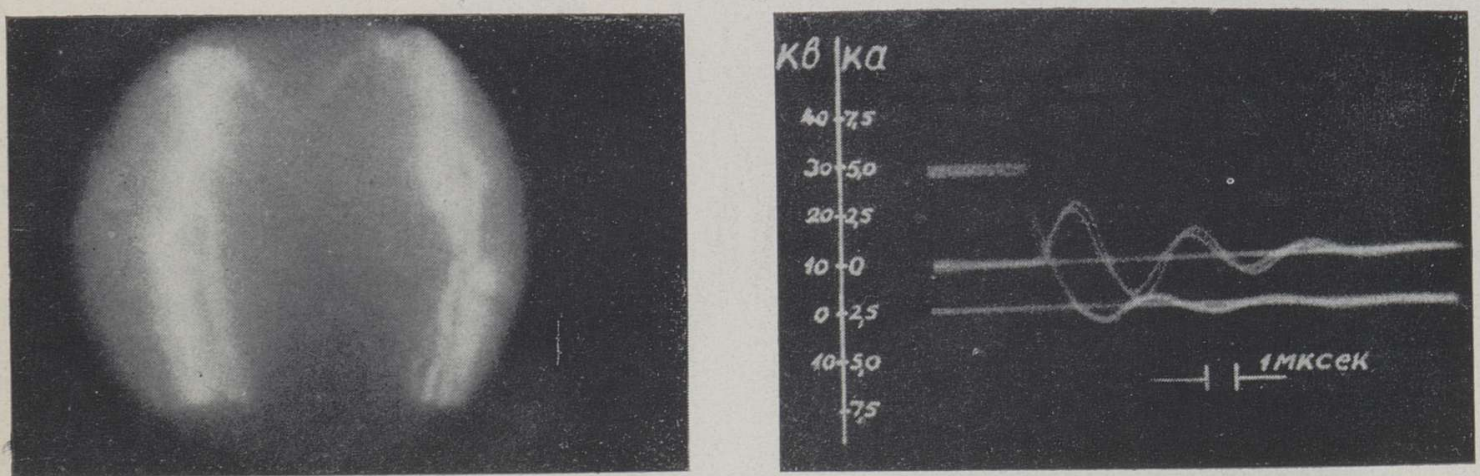

Рис. 3. Осциллограммы и интегральная фотография разряда в растворе метиленового голубого при $C=0,1$ мкф; $U=30 \kappa в ; l=15$ мм $\stackrel{+}{\rightarrow}-$. На каждом кадре
зафиксировано по два импульса. 

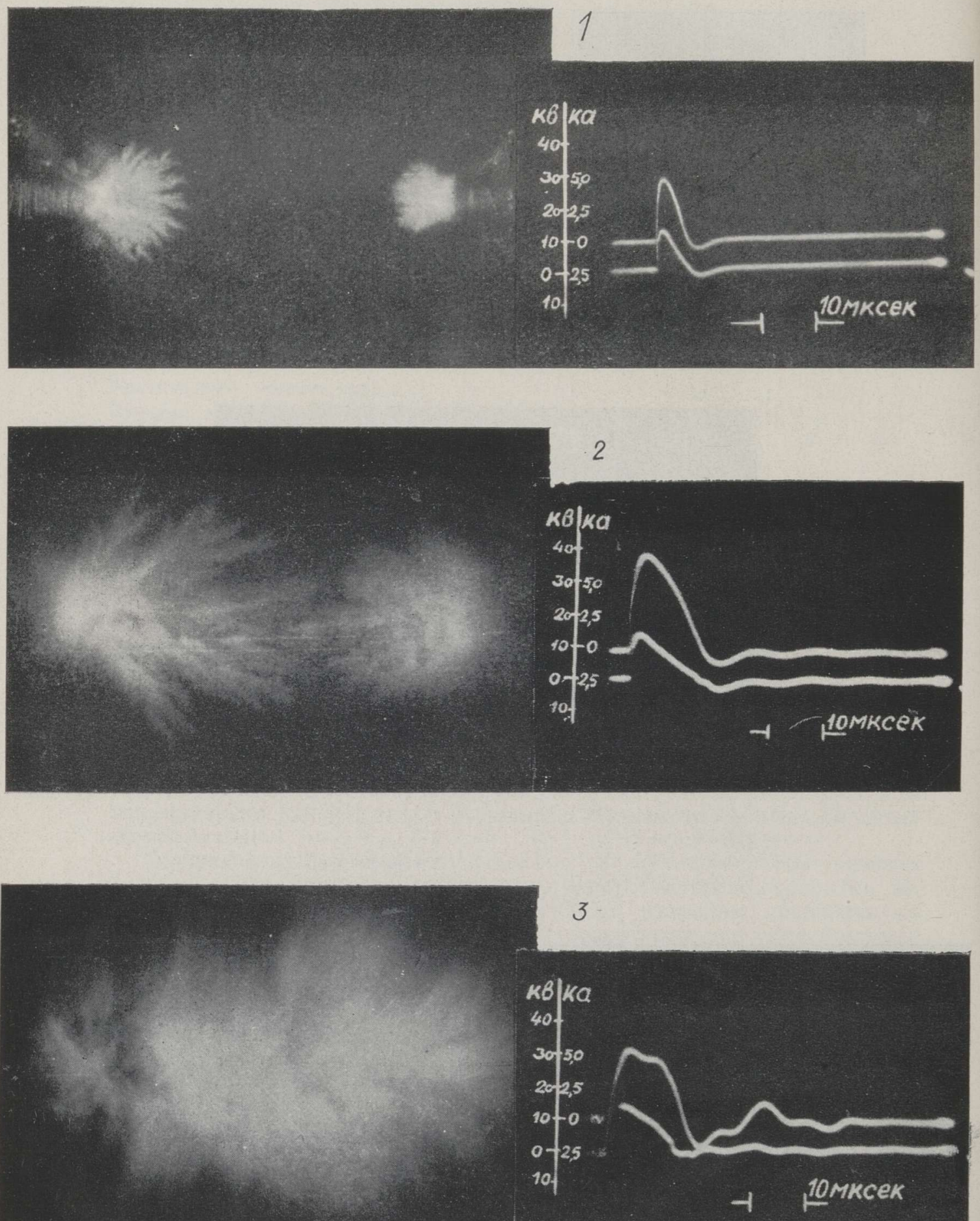

Рис. 5. Осциллограммы и интегральные фотоснимки разрядов для раствора Фрике при емкости: $1-0,6 ; 2-1,8 ; 3-2,4$ мкф. Расстояние между электродами острие-острие - 10 м.. 
Влияние предпробивного периода на параметры разряда в дистиллированной воде $(U=30 \kappa 8, l=15$ м $)$

\begin{tabular}{|c|c|c|c|c|c|}
\hline$\tau$, мксек & C, мкф & I. $\kappa a$ & $\begin{array}{c}\text { dildt } \\
\times 10^{9} \text { alcek }\end{array}$ & $T_{0} / 2$, мксек & $d$ \\
\hline $\begin{array}{l}1,8 \\
2,3 \\
7,3 \\
2,7 \\
4,3 \\
6.0 \\
2,3 \\
3,8\end{array}$ & $\begin{array}{l}0,1 \\
0,1 \\
0,1 \\
0,6 \\
0.6 \\
0,6 \\
1,2 \\
1,2\end{array}$ & $\begin{array}{l}2,5 \\
2,0 \\
1,5 \\
5,2 \\
4,3 \\
3,9 \\
8,2 \\
6,4\end{array}$ & $\begin{array}{l}2,9 \\
2.2 \\
0,6 \\
1,9 \\
1,2 \\
0,7 \\
3,2 \\
2,2\end{array}$ & $\begin{array}{l}1,8 \\
2,0 \\
2,1 \\
5,0 \\
7,0 \\
7,5 \\
7,2 \\
8,7\end{array}$ & $\begin{array}{l}0,93 \\
2,4 \\
\overline{-} \\
2,5 \\
- \\
- \\
-\end{array}$ \\
\hline
\end{tabular}

По данным [5], энергия ударных волн возрастает почти пропорционально увеличению крутизны тока di/dt. Поэтому при апериодических разрядах следует ожидать увеличения внутренней энергии канала, расходующейся на основные химические превращения среды.

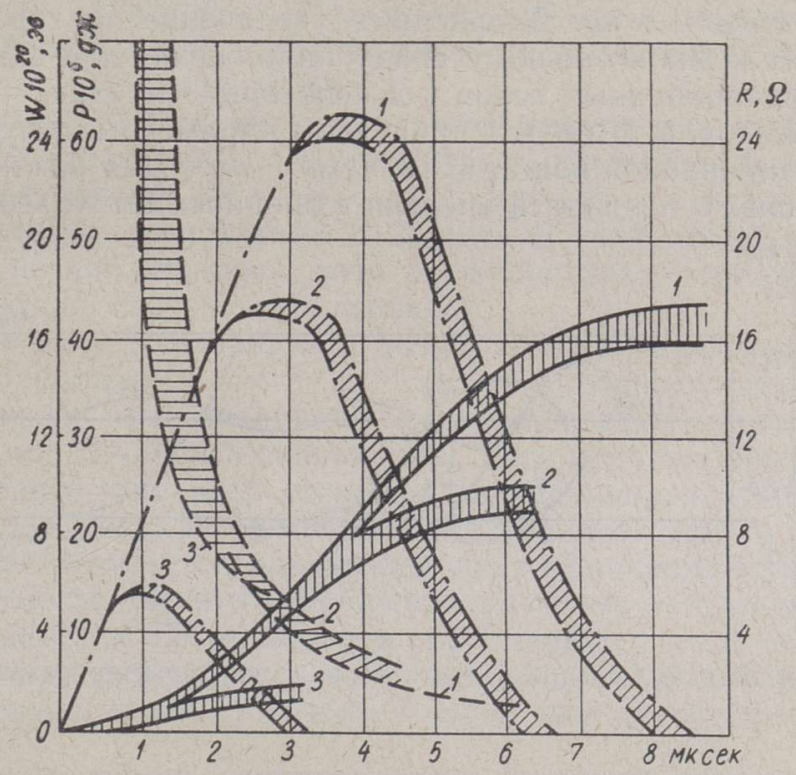

Рис. 2. Изменение мошности, энергии и сопротивления во времени для раствора метиленового голубого при различных емкостях: $1-2,4 ; 2-$ 0,$6 ; 3-0,1$ мкф.

\section{-. -. - мошность \\ - - энергия, выделяемая в канале \\ - - - сопротивление канала́}

Выявленные особенности апериодических разрядов позволяют считать их более эффективными с точки зрения ионизации среды и смягченными по ударно-волновому эффекту по сравнению с периодически-затухающими разрядами. Из приведенного обсуждения вытекает заключение, что решающую роль в физико-химическом воздействии на среду играет не столько энергия импульса, сколько характер разряда. 


\section{Предразрядные процессы в жидкости}

Опыт указывает на значительную нестабильность характеристик импульсного разряда в жидких средах. Это связано в основном со случайными элементарными процессами, развивающимися в предразрядный период. Длительность предпробивного периода при одинаковых условиях эксперимента незакономерно изменяется в значительных пределах.

На многих осциллограммах, у которых почти совпадает предразрядное время,'характер разряда приблизительно одинаков, сходна и форма самосветящихся каналов (см. рис. 3, где на одном кадре зафиксированы два импульса со скважностью в одну секунду).

Удлинение предразрядного периода при прочих равных условиях эксперимента обусловливает увеличение длины пути канала, уменьшение предпробивного напряжения и более пологий спад его, уменьшение амплитуды тока. На рис. 4 представлены осциллограммы, показывающие влияние абсолютных значений предпробивного времени на характер пробоя. На один кадр пленки подано четыре импульса. Увеличение тпр от 1,8 до 7,3 мксек приводит к изменению характера разряда от периодически-затухающего с декрементом затухания $d=0,93$ и $J_{\mathrm{m}}=2,5$ ка к апериодическому с $J_{\mathrm{M}}=1,5 \kappa$. Дальнейшее увеличение предпробивного периода приводит к значительному спаду напряжения (до $20 \%$ от $U_{c}$ ), к увеличению предпробивных токов и в некоторых случаях - к стеканию заряда конденсаторов. В табл. 1 приведены параметры импульсного разряда в дистиллированной воде $\gamma=10^{-5} O M^{-1} \cdot C M^{-1}$ для различных значений предпробивного периода и энергии единичных импульсов.

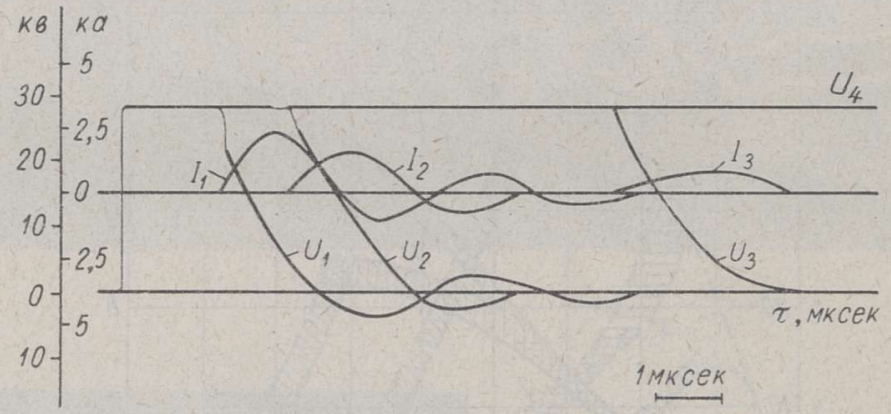

Рис. 4. Влияние предразрядного периода на характер разряда.

Несмотря на нестабильность предразрядных процессов, проведенные исследования позволили наметить отдельные закономерности. В основном длительность предпробивных процессов определяется электрофизическими свойствами среды, напряжением и межэлектродным расстоянием [1].

Установлена возможность управления длительностью предпробивных процессов в широких пределах от нескольких микросекунд до сотен микросекунд при соблюдении постоянства энергии единичного импульса и электропроводности среды. К удлинению продолжительности предпробивных процессов приводит: а) увеличение расстояния между электродами; б) увеличение неизолированной поверхности у электродов; в) замена электродов острие-плоскость на острие-острие.

Изменение расстояния между электродами (положительное остриеплоскость) с 8 до 30 мм в растворе с проводимостью $5 \cdot 10^{-4} \mathrm{om}^{-1} \cdot \mathrm{cm}^{-1}$ при подаче импульсов $U=30 \kappa в, C=0,6$ мкф, $L=3,6$ мкгн приводит к 
увеличению продолжительности предпробивного периода с 3 до 150 мксек. Увеличение неизолированной поверхности электрода с 1,75 до $300 \mathrm{~m}^{2}$ при неизменных параметрах импульсов приводит к возрастанию $\tau_{\text {пр }} \mathrm{c}$ нескольких микросекунд до 200 мксек. Дальнейшее увеличение площади контактной поверхности во избежание стекания заряда конденсаторов требует повышения напряжения.

Увеличение длительности предразрядных процессов до нескольких сотен микросекунд представляет специальный интерес, так как в этот период может происходить значительное выделение энергии - до 30 $40 \%$ от энергии, запасенной в конденсаторах.

Выделение энергии в предпробивном периоде вызывает интенсивную ионизацию в большом объеме жидкости при относительно низких температурах и способствует развитию определенных химических реакций.

\section{Особенности разряда в сильнопроводящих жидкостях}

Исследование влияния электропроводности жидкости на процессы развития разряда изучено небольшим числом исследователей $\left[{ }^{1,4}\right]$. Отмечено, что с повышением электропроводности снижаются значения критических напряжений, увеличивается число и яркость ветвей и уменьшается скорость развития лидера.

Г. Остроумов с сотрудниками $\left[{ }^{1,4}\right]$ обнаружили ряд особенностей развития разряда в различных электролитах и показали, что в жидкостях с проводимостью свыше $10^{-1} o^{-1} \cdot c M^{-1}$ пробой отсутствует даже при малых разрядных промежутках $(0,25$ мм). В указанных условиях срыва напряжения не наблюдалось, хотя токи достигали высоких значений; имело место лишь свечение у электрода.

При исследовании разрядов в дозиметрическом растворе Фрике [8] с электропроводностью $0,1 \quad \boldsymbol{M}^{-1} \cdot C \boldsymbol{M}^{-1}$ (кислая ферросульфатная система) нами обнаружен при различной длине разрядных промежутков (до 15 мм) срыв напряжения и скачок тока, хотя предпробивной процесс носит своеобразный характер стекания заряда конденсаторов. На рис. 5 представлены в качествс примера осгінллграммы тока и напряжения и соответствующие им интегральные фотоснимки разряда в растворе Фрике.

Установлено также, что особенность развития разрядов в сильнопроводящих жидкостях заключается в образовании густой сети самосветящихся ветвей, развивающихся от острия при любой полярности. Интенсивность свечения ветвей у огтрия больше, чем на периферийных участKax.

Положительному импульсу напряжения соответствуют бо́льшая скорость развития ветвей и значение амплитуд тока. Так, с повышением емкости с 0,0044 до 2,4 мкф́, в случае острия положительной полярности, ток увеличивается с 1,1 до $8,2 \kappa a$, а при изменении полярности - с 0,8 до $6,4 \kappa a$.

Увеличение емкости при неизменном напряжении приводит к интенсификации иәнизационных процессов и расширению сферической зоны при незначительном увеличении густоты ветвей. Перекрытие межэлектродного пространства происходит путем преобладающего развития одной или нескольких ветвей, близко расположенных друг к другу (остриеострие).

В случае системы острие-плоскость развитие ветвей начинается от острия и только в непосредственной близости к плоскости выделяется одна или несколько ветвей, перекрывающих промежуток. При дальнейшем незначительном увеличении емкости происходит плазменный про- 
бой. Наблюдаемое интенсивное образование газовых пузырей связано с нагревом жидкости (вскипанием) токами проводимости.

В табл. 3 приведены изменения основных показателей процесса в растворе Фрике при увеличении емкости в разрядной цепи с 0,0044 до 2,4 мкф (до образования пробоя).

\section{Основные показатели импульсных разрядов в растворе Фрике}

$$
\nu=0,1 \text { oм }^{-1} \cdot c M^{-1}(U=30 \mathrm{\kappa}, l=15 \mathrm{MM} \stackrel{+}{\rightarrow} \mapsto)
$$

\begin{tabular}{|c|c|c|c|c|c|}
\hline & \multicolumn{5}{|c|}{ Емкость, $и к ф$} \\
\hline & 0,0044 & 0,1 & 0,6 & 1.2 & 2,4 \\
\hline 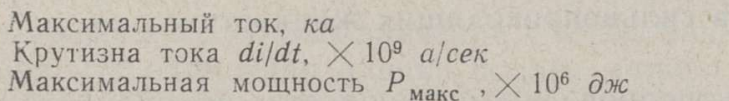 & $\begin{array}{l}1,1 \\
3.0 \\
4.8\end{array}$ & $\begin{array}{c}2,8 \\
2,9 \\
18\end{array}$ & $\begin{array}{r}5.1 \\
2.8 \\
55\end{array}$ & $\begin{array}{r}6.5 \\
2.5 \\
78\end{array}$ & $\begin{array}{r}8,2 \\
2,5 \\
105\end{array}$ \\
\hline $\begin{array}{l}\text { Продолжительность разряда } \tau \text {, мксек } \\
\text { Минимальное сопротивленне межэлектродного } \\
\text { промежутка } R_{\text {мин }} \text {, ом }\end{array}$ & $\begin{array}{l}0,4 \\
2,0\end{array}$ & 1,8 & $\begin{array}{l}4,8 \\
1,6\end{array}$ & $\begin{array}{l}7,1 \\
1,2\end{array}$ & $\begin{array}{l}11,3 \\
0,9\end{array}$ \\
\hline Энергия единичного импульса, $W \times 10^{20}$ эв & 0,07 & 1,24 & 8,6 & 15,6 & 31,5 \\
\hline
\end{tabular}

О значительной роли ионизационных процессев в сильно проводящих жидкостях под действием импульсных разрядов - до образования плазменного пробоя - свидетельствуют результаты определения выхода окисленного железа в зависимости от мощности дозы, которая сопоставима с данными радиационно-химических исследований [8].

Более подробно результаты исследования развития разрядов в сильнопроводящих жидкостях будут изложены в следующем сообщенин.

\section{Выводы}

1. Предпробивные прощессы оказывают существенное влияние на характер развития разрядов в пробивной стадии. Возможна такая организация процесса с перераспределением энергии в отдельных стадиях, когда с увеличением длительности предпробивного периода доля расходуемой в нем энергии от общей энергии, запасенной в конденсаторе, значительно возрастает. Это приводит к существенному уснлению ионизации жидкости и расширению ионизационной зоны, т. е. содействует протеканию в среде соответствующих химических реакций.

2. Основную роль в физико-химическом воздействии импульсов высокого напряжения на среду играет характер разряда. Выявленные особенности апериодического разряда позволяют считать его более перспективным для этих целей.

3. Осуществление плазменного пробоя возможно и в сильнопроводящих жидкостях. Он отличается своеобразным «предпробивным» пєриодом: вскипанием жидкости, интенсивным образованием газовых пузырей и прорастанием густой сети самосветящихся ветвей - почти до перекрытия межэлектродного пространства. Эти явления приводят к значительнсй ионизации среды (раствора Фрике). 


\section{Л ИТЕ РА Т У Р А}

1. Пробой диэлектриков и полупроводников, Сб. докл. IV Межвузовской конференџин, М., 1964.

2. Балыгин И. Е., Электрнческая крепость жидких диэлектриков, М., 1964.

3. $\mathrm{M}$ a r t in E., J. Appl. Phys., 32, No. 2 (1960).

4. Мельников Н. П., О с р о мов Г. А., Ш тейнберг А. А., Докл. АН СССР, 147, № 4, 822 (1962); Тр. Лен. гос. ун-та, 1962.

5. Комельков В. С. и др. Ж. техн. физ., 31, № 8, 948 (1961); Ж. техн. физ., 30 , № 10,1168 (1960).

6. С текольников Н. Е., Ушаков В. Я., Ж. техн. физ., 25, 9, 1695 (1965).

7. Гу бергриц М. Я., Бродская Б. Х., Па а льме Л. П., См. наст. номер журнала, стр. $465-475$.

8. Аллен А. О., Радиационная химия воды и водных растворов, М., 1963.
Ннститут химии
Академии наук Эстонской ССР
Поступила в редакцию 19/III 1966

\section{B. BRODSKAJA}

\section{IMPULSSLAHENDUSE TOIMEST DOSIMEETRILISTELE VESILAHUSTELE IMPULSI ERINEVATEL PARAMEETRITEL}

Artiklis esitatakse katselise uurimistöö tulemused impulsslahenduse toime kohta dosimeetrilistele vesilahustele (elektrijuhtivusega $\gamma=10^{-5} \div 10^{-1} \Omega^{-1} \cdot \mathrm{cm}^{-1}$ ) impulsi erine. vatel parameetritel $(\mathrm{C}=0,0044 \div 2,4 \mu \mathrm{F} ; \mathrm{U}=30 \mathrm{kV})$.

Hästi juhtivates keskkondades selgitati mitmeid lahenduste arenemise iseärasusi ja näidati plasmalise läbilöögi olemasolu võimalikkust.

Vaadeldakse lahenduse algprotsessi sidet lahenduse arenemise iseloomuga ja energia ümberjaotamise võimalikkust üksikute staadiumide vahel.

Esitatakse andmed lahenduse iseloomu ja tema parameetrite mõju kohta keskkonnale toimiva füüsikalis-keemilise protsessi efektiivsusele.

\section{B. BRODSKAYA}

\section{STUDY OF PULSE DISCHARGE IN AQUEOUS SOLUTIONS OF HIGH ELECTRICAL CONDUCTIVITY}

The effects of pulse discharges with various discharge parameters ( $U=30 \mathrm{kv}$, $\mathbb{C}=0,0044 \div 2.4 \mu \mathrm{F}$ ) upon dosimetric aqueous solutions with high electrical conductivity $\left(\gamma=10^{-5}-0.1 \Omega^{-1} \cdot \mathrm{cm}^{-1}\right)$ are described. Some peculiarities of discharge development in fighly conductive media and the possibility of a plasma breakdown are given. The relations between processes preceding breakdown and various breakdown characteristics are described. A possibility of energy redistribution between these stages is indicated. Some quantitative relations between discharge characteristics and respective physico-chemical effects in solutions have been established. 